\title{
Effects of Feeding Milk Replacer Once Versus Twice Daily on Glucose Metabolism in Holstein and Jersey Calves ${ }^{1}$
}

\author{
C. C. Stanley, ${ }^{\star}$ C. C. Williams, ${ }^{\star}$ B. F. Jenny, ${ }^{\star}$ J. M. Fernandez,† H. G. Bateman, II, ${ }^{\star}$ W. A. Nipper,‡ \\ J. C. Lovejoy§, D. T. Gantt, ${ }^{\star}$ and G. E. Goodier* \\ *Department of Dairy Science and \\ †Department of Animal Science, \\ Louisiana State University Agricultural Center, \\ Louisiana Agricultural Experiment Station, \\ Baton Rouge, 70803 \\ †Hill Farm Research Station, \\ Louisiana State University Agricultural Center, \\ Homer, 71040 \\ §Pennington Biomedical Research Center \\ Louisiana State University, \\ Baton Rouge 70803
}

\begin{abstract}
Eighteen Holstein (experiment 1) and 15 Jersey (experiment 2) heifer calves were fed milk replacer once or twice daily to determine effects of feeding frequency on weight gain, starter intake, and glucose metabolism. Body weights were measured weekly from birth to 8 wk. Blood samples were collected at wk 1 through 6 from all calves before and at 30,60, 90, 120 and 180 min after the morning feeding. Plasma was analyzed for glucose, insulin, glucagon, and nonesterified fatty acids (NEFA). Urine was collected 90 min postfeeding to measure glucose concentration. Treatment did not affect mean starter intake or body weight. In experiments 1 and 2 mean plasma glucagon, glucose, NEFA, and insulin and urinary glucose concentrations were not affected by treatment. There was an interaction of sampling time and treatment for plasma insulin concentrations but not for glucose concentrations in both experiments. Following feeding, calves fed milk replacer once daily had higher insulin concentrations than those fed twice daily. There was an interaction of sampling time and treatment for plasma NEFA concentrations in Jersey calves only. Jersey calves fed milk replacer once daily had higher plasma NEFA concentrations before the morning milk replacer feeding. At wk 3 and 6 , frequently sampled intravenous glucose tolerance tests were performed to assess glucose effectiveness, insulin sensitivity, and acute insulin response. In
\end{abstract}

Received October 2, 2002.

Accepted April 10, 2002.

Corresponding author: C. C. Williams; e-mail: cwilliams@ agctr.lsu.edu.

${ }^{1}$ Approved by the director of The Louisiana Agricultural Experiment Station as Publication N 02150058. experiments 1 and 2 glucose effectiveness and insulin sensitivity were similar regardless of milk replacer feeding frequency. In Holstein and Jersey calves fed milk replacer twice daily, acute insulin response was greater than in calves fed once daily. However, insulin sensitivity decreased with age, while acute insulin response increased with age. These data suggest that feeding calves milk replacer once daily did not deleteriously affect performance or glucose metabolism regardless of breed.

(Key words: heifer calf, milk replacer feeding frequency, glucose metabolism)

Abbreviation key: $\mathbf{A I R}_{\text {glucose }}=$ acute insulin response, FSIGT = frequently sampled intravenous glucose tolerance test, $\mathbf{M R}=$ milk replacer, $\mathbf{S}_{\mathbf{G}}=$ glucose effectiveness, $\mathbf{S}_{\mathbf{I}}=$ insulin sensitivity.

\section{INTRODUCTION}

In nonruminants and pseudo-nonruminants, such as young calves, ingestion of feed and absorption of glucose stimulate the secretion of insulin, which decreases hepatic gluconeogenesis while promoting tissue uptake of glucose and other blood components (Guyton and Hall, 1996). Glucose intolerance, characterized by abnormally increased glucose and sometimes elevated insulin concentrations, can develop in intensively fed veal calves (Webb et al., 1969; Hostettler-Allen et al., 1994). Glucosuria has also been observed in intensively fed veal calves, indicating a loss of energy (Hostettler-Allen et al., 1994).

In addition to milk replacer (MR), conventionally raised dairy calves are also fed calf starter, which has been shown to promote both physical and functional rumen development (Anderson et al., 1987). As calves develop into fully functioning ruminants, hepatic gluco- 
neogenesis increases and becomes the primary pathway of hepatic metabolism as the result of an increase in VFA production and absorption (Owens et al., 1986). In conventionally raised dairy calves, glucose concentrations decline with age (DePew et al., 1998; Bunting et al., 2000). In studies performed by Bunting et al. (2000) and DePew et al. (1998), in which calves were weaned at $5 \mathrm{wk}$, insulin concentrations increased with age. Donkin and Armentano (1995) reported that insulin concentrations declined as calves transformed from the preruminating state to the ruminating state. Previous research has shown that feeding MR once daily reduces labor without affecting health, weight gain, or starter consumption of calves (Galton and Brakel, 1976). We are unaware of any data comparing the effects of feeding MR once daily versus twice daily on glucose metabolism in neonatal dairy calves. Calves fed MR once daily will consume more nutrients in a single feeding and could respond similarly to intensively fed veal calves. Two experiments were designed to compare glucose tolerance and insulin resistance in Holstein (experiment 1) and Jersey (experiment 2) heifer calves fed MR once daily versus twice daily.

\section{MATERIALS AND METHODS}

\section{Animals and Dietary Treatments}

Two experiments were performed to assess the effects of feeding MR once or twice daily on performance and glucose metabolism in neonatal heifer calves. In experiment 1, 18 Holstein calves were born and housed at the Dairy Science Research and Teaching Farm in Baton Rouge, Louisiana, between October, 1999, and June, 2000. In experiment 2, 15 Jersey heifer calves were born and housed at the Hill Farm Research Station in Homer, Louisiana, between January, 2000 and July, 2000. The experimental protocols were approved by the Institutional Animal Care and Use Committee of the LSU Agricultural Center.

In experiment 1 , calves were removed from their dams, weighed, and placed in individual calf hutches within $12 \mathrm{~h}$ of birth. Calves received $1.9 \mathrm{~L}$ of colostrum at each of the first two feedings and were trained to drink milk from buckets during the first $3 \mathrm{~d}$ of life. Refused colostrum was fed via esophageal feeding tube. In experiment 2, calves were allowed to suckle their dams during their first $24 \mathrm{~h}$ of life. Calves were weighed and placed in individual calf hutches on $\mathrm{d} 2$ and were fed MR from nipple pails.

In both experiments 1 and 2, calves were fed a commercial MR twice daily during the first week of life. The MR (Nursetrate NT-P; Mormans, Inc., Quincy, IL) contained $22 \% \mathrm{CP}$ and $15 \%$ crude fat and was medicated (220 g of oxytetracycline and $485 \mathrm{~g}$ of neomycin base per metric tonne). Milk replacer powder was reconstituted to $15 \% \mathrm{DM}$ and fed at a rate $10 \%$ of initial BW in two equal feedings per day. Calves were offered a commercial calf starter twice daily for ad libitum consumption to a maximum intake of $2.64 \mathrm{~kg} / \mathrm{d}$. Feed refusal was measured daily. Water was offered daily for ad libitum consumption.

In both experiments, calves began their treatment protocols at approximately $1 \mathrm{wk}$ of age. Calves assigned to treatment 1 (experiment $1, \mathrm{n}=9$; experiment $2, \mathrm{n}=$ 8) continued to receive MR twice daily at the initial concentration. Calves assigned to treatment 2 (experiment $1, \mathrm{n}=9$; experiment $2, \mathrm{n}=7$ ) were offered the same quantity of MR powder in one feeding daily. The amount of water used to reconstitute MR for calves fed once daily was reduced by $30 \%$, yielding a final DM concentration of the MR of $21.4 \%$ as compared with $15.0 \%$ in calves fed twice daily. At 5 wk of age, the total volume of reconstituted MR offered was reduced by $50 \%$ for all calves. Calves were abruptly weaned at $6 \mathrm{wk}$ of age.

\section{Sample Collection and Frequently Sampled Intravenous Glucose Tolerance Tests}

All calves were weighed at birth and once weekly from wk 1 to 8. Jugular blood was collected into evacuated tubes containing potassium oxalate and sodium fluoride (Kendall Medical, St. Louis, MO) during wk 1 to 6 and wk 8 of age from all calves immediately prior to and at 30,60,90, 120, and $180 \mathrm{~min}$ after the a.m. feeding. Tubes were centrifuged, and plasma was frozen until analyzed for glucose, insulin, and NEFA concentrations. An additional blood sample was taken before the morning feeding for plasma glucagon analysis. This sample was collected into an evacuated tube containing sodium salts of EDTA (Kendall Medical, St. Louis, MO), and aprotinin (Sigma Chemical, St. Louis, MO) was added to deliver 5 trypsin inhibiting units. Urine samples were collected at 90 min postfeeding by manual stimulation of the perineum from calves and stored at $-20^{\circ} \mathrm{C}$ until analysis for glucose.

The frequently sampled intravenous glucose tolerance tests (FSIGT) (Bergman, 1997) were performed at weeks 3 and 6 in all calves. Calves were fitted with $14 \mathrm{G} \times 5.1 \mathrm{~cm}$ jugular catheters (Baxter Healthcare Corporation, Deerfield, IL) at least $1 \mathrm{~h}$ before the test. The test consisted of intravenous administration of glucose (300 mg/kg of BW) followed 19 min later by intravenous administration of bovine insulin (0.03 IU/kg of BW). Blood samples were collected via jugular catheter at $-10,0,2,4,8,12,19,22,30,40,50,60,70,80,90,120$, 150 , and $180 \mathrm{~min}$ relative to glucose administration. Blood samples were placed in 7-ml evacuated tubes 
containing potassium oxalate and sodium fluoride (Kendall Medical, St. Louis, MO) and were centrifuged, and plasma was separated and frozen at $-20^{\circ} \mathrm{C}$ until analysis.

\section{Laboratory Methods}

Using commercial spectrophotometric kits, plasma was analyzed for glucose (Sigma Tech. Bull. No. 315; Sigma Chemical, St. Louis, MO) and NEFA concentrations (NEFA-C Kit, ACS-ACOD Method; Wako Chemicals, USA, Richmond,VA) as modified by Drackley et al. (1991). Plasma insulin concentrations were measured using commercial radioimmunoassay kits (Coat-ACount; Diagnostic Products Corporation, Los Angeles, CA) as validated for cattle by Vicini et al. (1991). Plasma was analyzed for glucagon using commercial radioimmunoassay kits (Linco Research, Inc., St. Louis, MO) as described by Hammon and Blum (1998). Intra-assay $\mathrm{CV}$ for the insulin and glucagon assays were 3.6 and $4.1 \%$, respectively. Inter-assay CV for the insulin and glucagon assays were 1.1 and $2.2 \%$, respectively

\section{Statistical Methods and Calculations}

Data for BW and starter intake from both experiments were reduced to weekly means prior to analysis by ANOVA using a mixed model (Littell et al., 1998). For each experiment the model used to analyze these data included terms for fixed effects of birth weight, which was used as a covariate, treatment, week, and the interaction of treatment and week. Calf nested in treatment was included as a random variable that was used as the error term for the main effect of treatment. Week was modeled as a repeated term that was assumed to be correlated within calf using a type I autoregressive covariance structure.

The minimal modeling computer procedure was used to assess glucose effectiveness $\left(\mathbf{S}_{\mathbf{G}}\right)$, the fractional glucose disappearance at basal insulin concentration independent of changes in insulinemia; insulin sensitivity $\left(\mathbf{S}_{\mathbf{I}}\right)$, which is the effect of an incremental change in plasma insulin to increase the fractional glucose disappearance rate of glycemia; and the acute insulin response relative to glucose administration ( $\mathbf{A I R}_{\text {glucose }}$ ) (Bergman, 1997). The FSIGT and metabolite data from both experiments were analyzed by ANOVA using a mixed model (Littell et al., 1998). The model included fixed effects of treatment, week, and the interaction of treatment and week. Calf nested in treatment was included as a random variable and used as error term for main effect of treatment. Week was modeled as a repeated term that was assumed to be correlated within calf with a constant covariance structure. For glucagon and urine data, week was modeled as a repeated term that was assumed to be correlated within calf using a type I autoregressive covariance structure. For insulin, glucose, and NEFA data, week and sample hour were modeled as repeated terms. Both were assumed to be correlated within calf with a type I autoregressive covariance for structure for week and a constant covariance structure for sample hour. All calculations were completed using SAS (1989).

\section{RESULTS AND DISCUSSION}

\section{Performance Data}

Least squares means for average daily starter intake, starter intake as a percentage of BW, and birth, weaning, and end of trial BW of calves are presented in Table 1. Least squares means for starter intake $(\mathrm{g} / \mathrm{d})$ for the 8 wk are presented in Figure 1. Least squares means for weekly BW for the 8 wk are presented in Figure 2. There were no MR feeding frequency $\times$ week interactions for starter intake $(P>0.10)$ or BW $(P>0.10)$ in either Holstein or Jersey calves. Average daily starter intake, starter intake as a percentage of BW, and BW were not affected $(P>0.10)$ by MR feeding frequency in either experiment. Birth weight tended to be higher $(P=0.06)$ in Holstein calves fed MR once daily. After weights were covariant adjusted to compensate for differences in birth weights, no differences were detected in weaning $(P>0.10)$ or end of trial weights $(P>0.10)$ for calves fed MR once or twice daily in either experiment.

\section{Weekly Metabolite Data}

Milk replacer feeding frequency. Least squares means for plasma concentrations of glucose, insulin, NEFA, glucagon, and urinary glucose concentrations of calves in both experiments are reported in Table 2. Urinary and plasma glucose, and plasma NEFA, insulin, and glucagon concentrations were not affected $(P$ $>0.05$ ) by milk replacer feeding frequency. Most calves had nondetectable concentrations of urinary glucose, which was coded as zero for statistical analysis. The low concentrations of glucose in urine indicate that blood glucose levels did not reach the estimated renal threshold of 150 to $200 \mathrm{mg} / \mathrm{dl}$ (Hostettler-Allen et al., 1994; Wijayasinghe et al., 1984). Calves fed MR once daily did not demonstrate glucosuria, hyperinsulemia, or hyperglycemia as previously reported in intensively fed veal calves (Hostettler-Allen et al., 1994; Hugi et al., 1997). Plasma glucose concentrations were numerically higher in Holstein than in Jersey calves, but NEFA concentrations were numerically greater in Jersey than in Holstein calves. Plasma concentrations of insulin and glucagon appeared to be similar for the two breeds. 
Table 1. Least squares means for starter intake and $B W^{1}$ of calves fed milk replacer $(\mathrm{MR})$ once $(1 \times)$ or twice $(2 \times)$ daily.

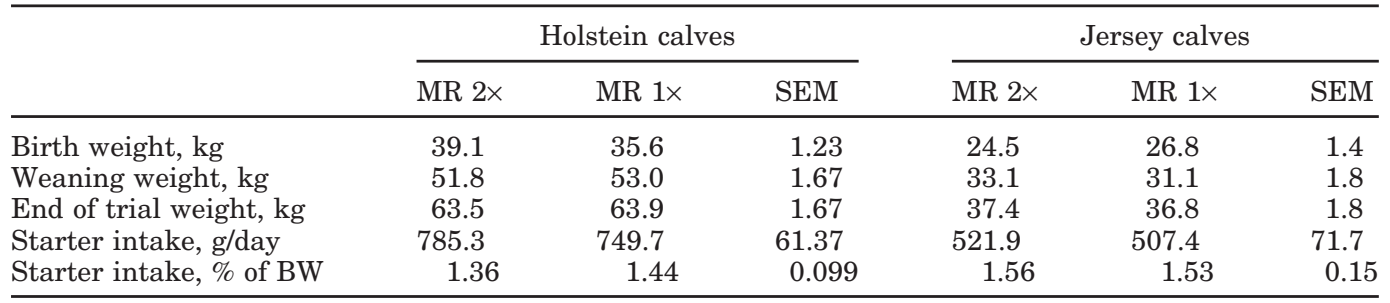

${ }^{1}$ Birth weights are unadjusted means while weaning and end of trial weights are covariant adjusted to compensate for differences in birth weight.

Least squares means for plasma glucose and insulin concentrations relative to the MR feeding for calves fed MR once or twice daily are presented in Figures 3 and 4, respectively. In both Holstein and Jersey calves, there was not an interaction of sampling time and MR
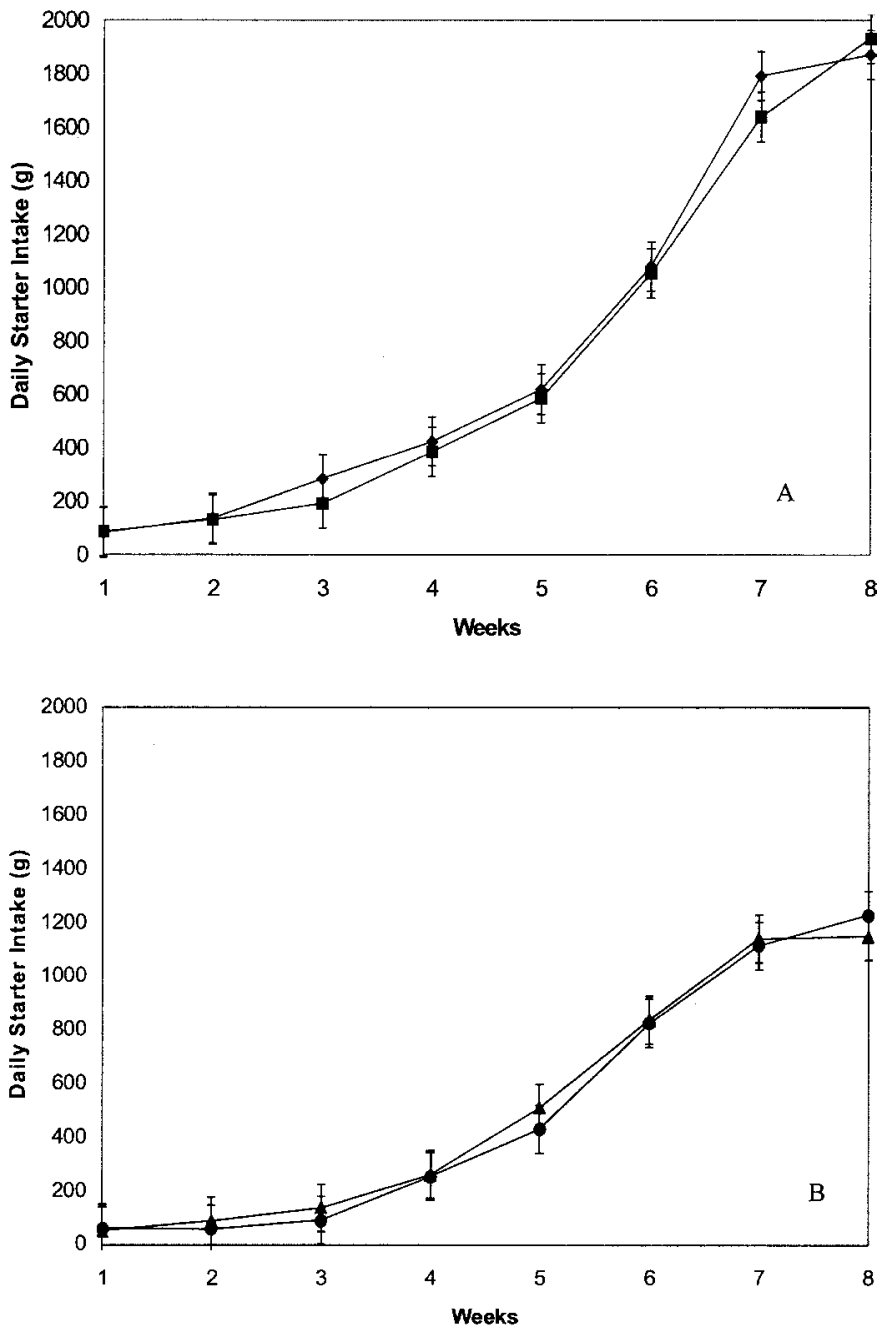

Figure 1. Starter intake of Holstein (A) or Jersey (B) calves fed milk replacer once ( $\boldsymbol{\square}$ and $)$ or twice ( and $\mathbf{\Delta}$ ) daily. feeding frequency for glucose concentrations $(P>0.10)$. The peak glucose concentration relative to the morning MR feeding was at $30 \mathrm{~min}$ in Holstein calves and at 60 min in Jerseys calves, but was not affected by MR feeding frequency. In both Holsteins and Jerseys, there was an interaction of sampling time and MR feeding fre-
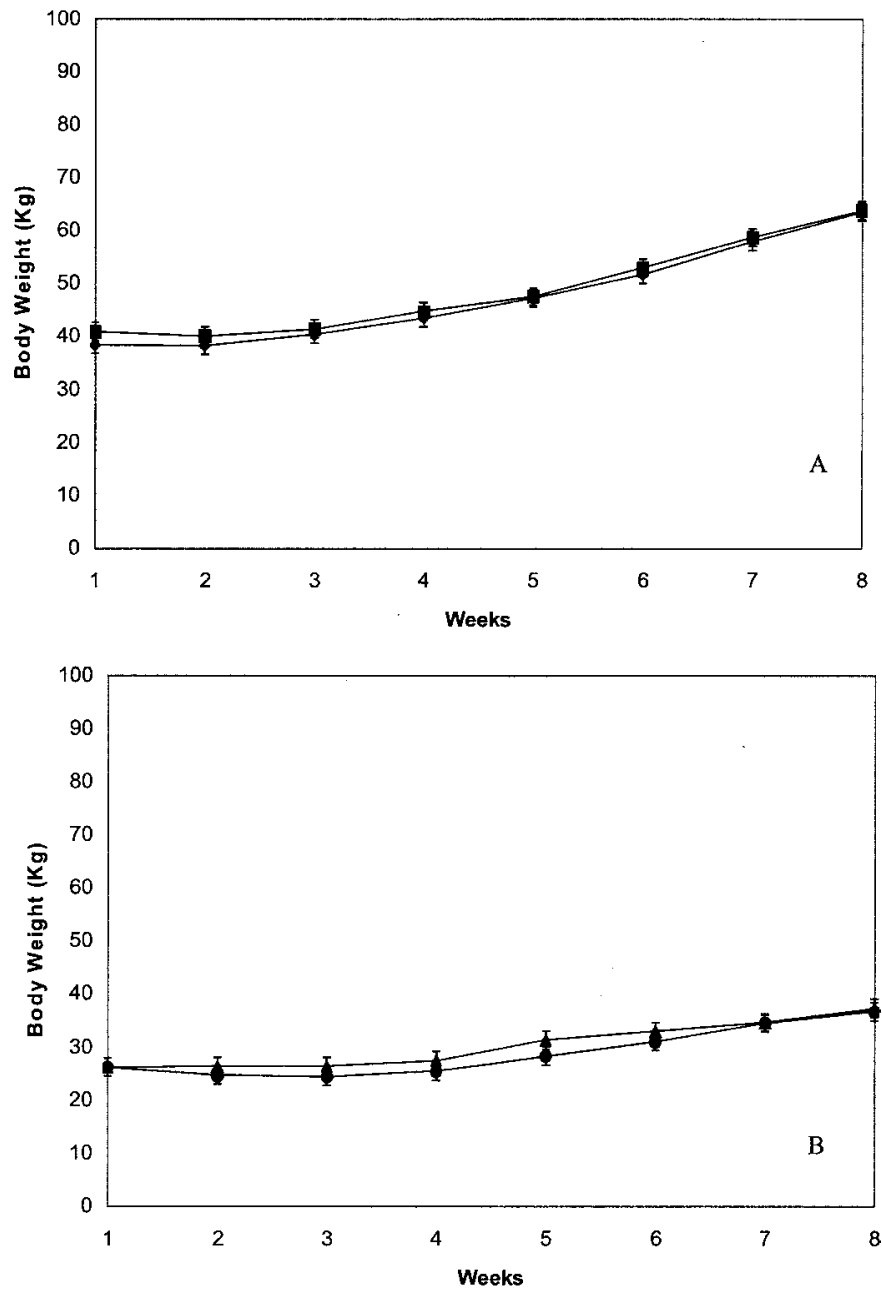

Figure 2. Weekly mean BW of Holstein (A) or Jersey (B) calves fed milk replacer once $(\boldsymbol{\square}$ and $)$ or twice $(\bullet$ and $\boldsymbol{\Delta})$ daily. 
Table 2. Least squares means for plasma and urine metabolite data for calves fed milk replacer (MR) once $(1 \times)$ versus twice $(2 \times)$ daily.

\begin{tabular}{|c|c|c|c|c|c|c|}
\hline & \multicolumn{3}{|c|}{ Holstein calves } & \multicolumn{3}{|c|}{ Jersey calves } \\
\hline & $\operatorname{MR} 2 \times$ & MR $1 \times$ & SEM & MR $2 \times$ & MR $1 \times$ & SEM \\
\hline Plasma glucose, $\mathrm{mg} / \mathrm{dl}$ & 83.4 & 84.5 & 2.4 & 78.7 & 77.3 & 1.9 \\
\hline Plasma insulin, $\mu \mathrm{IU} / \mathrm{ml}$ & 9.1 & 10.6 & 0.5 & 9.5 & 10.6 & 0.7 \\
\hline Plasma NEFA, meq/l & 0.20 & 0.20 & 0.01 & 0.28 & 0.29 & 0.02 \\
\hline Plasma glucagon, pg/ml & 82.1 & 88.8 & 8.5 & 76.3 & 90.4 & 11.27 \\
\hline Urine glucose, $\mathrm{mg} / \mathrm{dl}$ & 5.4 & 9.9 & 3.7 & 1.4 & 3.2 & 0.9 \\
\hline
\end{tabular}

quency for insulin concentrations $(P<0.05)$. In calves fed MR once daily, the highest concentration of insulin following the morning MR feeding was at 60 min postfeeding in Holstein calves and at 120 min postfeeding in Jersey calves. Since MR feeding frequency did not affect urinary or plasma glucose concentrations relative
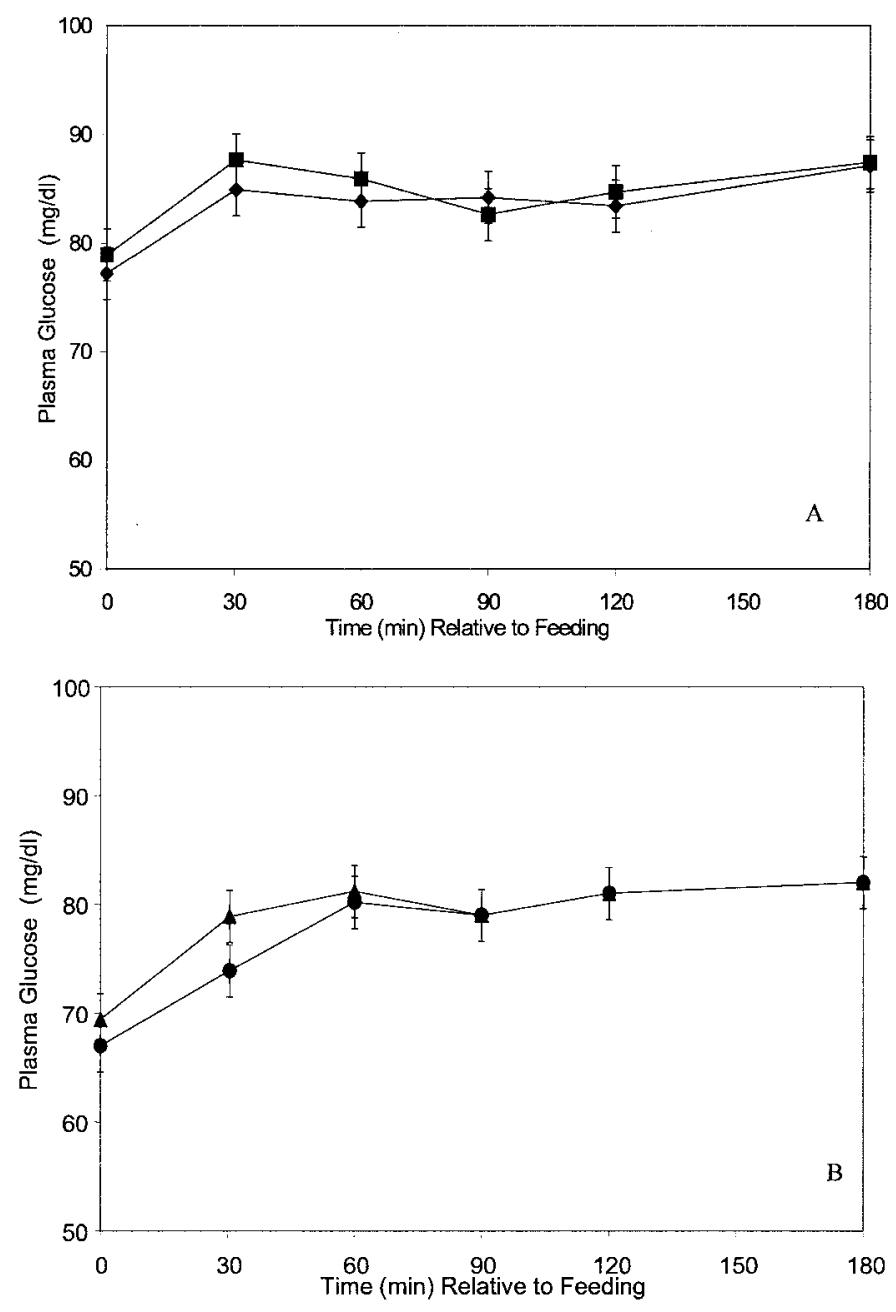

Figure 3. Least squares means for plasma glucose concentrations from Holstein (A) or Jersey (B) calves fed milk replacer once ( $\square$ and -) or twice ( and $\boldsymbol{\Delta}$ ) daily. to the morning MR feeding, it appears that higher insulin concentrations in calves fed MR once daily were effective in promoting glucose uptake. Calves fed MR once daily did not demonstrate glucosuria, or hyperglycemia as previously reported in intensively fed veal calves (Hostettler-Allen et al., 1994).
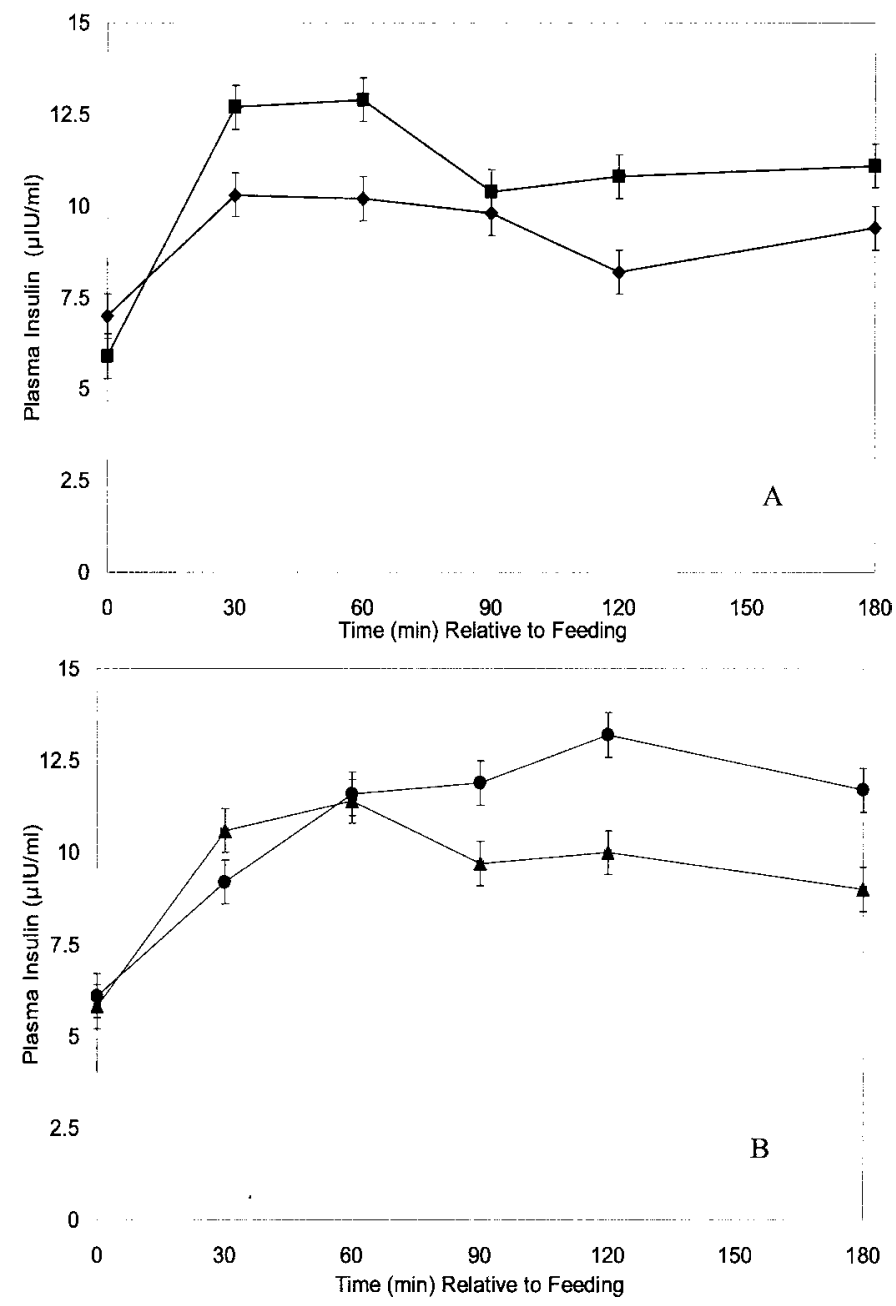

Figure 4. Least squares means for plasma insulin concentrations from Holstein (A) or Jersey (B) calves fed milk replacer once ( $\mathbf{\square}$ and -) or twice ( and $\boldsymbol{\Delta}$ ) daily. Interactions $(P<0.05)$ of sampling time and milk replacer feeding for Holsteins and Jerseys. 
Table 3. Least squares means for pre- and postfeeding plasma NEFA concentrations for Jersey calves fed milk replacer (MR) once $(1 \times)$ versus twice $(2 \times)$ daily. ${ }^{\mathrm{A}}$

\begin{tabular}{|c|c|c|c|}
\hline & \multicolumn{3}{|c|}{ Jersey calves } \\
\hline & MR 2× & MR 1× & SEM \\
\hline Prefeeding ${ }^{1}$ plasma NEFA, meq/1 & $0.29^{\mathrm{ac}}$ & $0.34^{\mathrm{bc}}$ & 0.02 \\
\hline Postfeeding ${ }^{2}$ plasma NEFA, meq/1 & $0.27^{\text {ad }}$ & $0.24^{\text {bd }}$ & 0.02 \\
\hline \multicolumn{4}{|c|}{$\begin{array}{l}{ }_{\mathrm{A}}^{\mathrm{A}} \text { Milk replacer feeding frequency } \times \text { time interaction }(P<0.05) . \\
\text { a,b Means within a row without a common superscript differ }(P< \\
0.05) \text {. } \\
\quad{ }^{\mathrm{c}, \mathrm{d}} \text { Means within a column without a common superscript differ }(P \\
<0.05) \text {. } \\
{ }^{1} \text { Collected immediately prior to a. m. MR feeding. } \\
{ }^{2} \text { Collected } 60 \text { min after a. m. MR feeding. }\end{array}$} \\
\hline
\end{tabular}

Jersey calves exhibited an interaction $(P<0.05)$ of sampling time and milk MR feeding frequency and week for plasma NEFA concentrations (Table 3). This interaction was not observed in Holstein calves $(P>$ 0.10). Jersey calves fed MR once daily had NEFA concentrations that were higher before the morning MR feeding than after this feeding while Holstein calves fed MR once daily and Holstein and Jersey calves fed MR twice daily had similar NEFA concentrations before and after the morning MR feeding. Previous research has shown that blood NEFA concentrations are negatively correlated with calf starter intake (Quigley, 1996). The differences in pre- and postfeeding NEFA concentrations observed in Jersey calves may be related to their feed intake. Jersey calves consumed less total feed than Holsteins; however, this intake was a larger percentage of their BW (Table1). Therefore, Jersey calves that were fed MR once daily were consuming proportionately more feed in a relatively short period of time compared with Jersey calves fed twice daily. It has been previously reported that NEFA are mobilized to maintain caloric homeostasis during times of fast (Webb et al., 1969). Jersey calves fed MR once daily had to rely on body stores for energy for a larger portion of the day than did Jerseys fed twice daily. The lack of this response in Holstein calves may be due to the absolute increase in feed consumed.

Age effect There was an interaction $(P<0.05)$ of week and sampling time for plasma NEFA concentrations in Holstein calves (Figure 5A). There was also a trend ( $P$ $=0.06$ ) for this interaction in Jersey calves (Figure $5 \mathrm{~B}$ ). For the first $3 \mathrm{wk}$ of life, prefeeding plasma NEFA concentrations were greater than postfeeding concentrations. By 3 wk of age, as the calves began to consume more starter, pre- and postfeeding plasma NEFA concentrations became similar. It has been proposed that NEFA are mobilized to maintain caloric homeostasis when there are no readily available energy sources
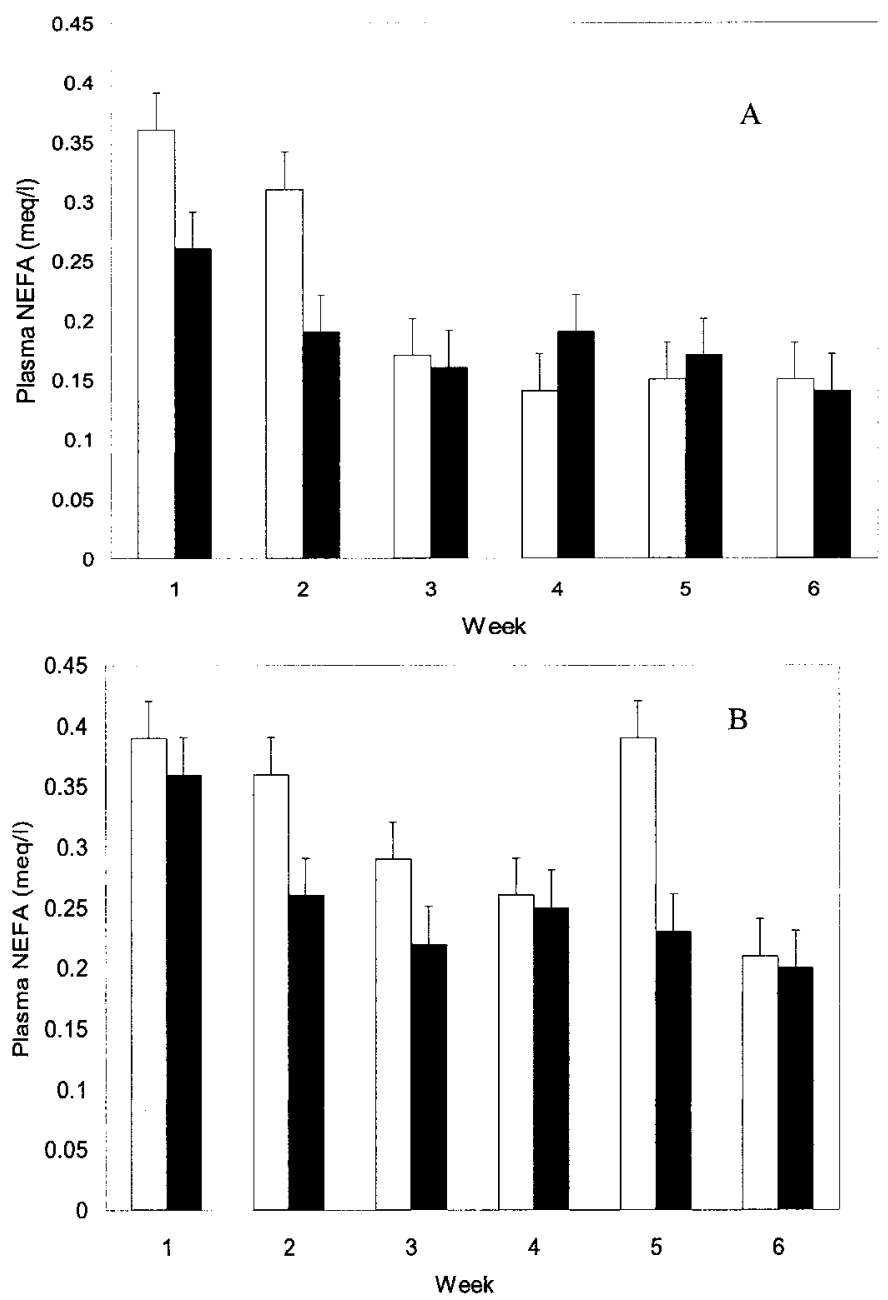

Figure 5. Least squares means for prefeeding $(\square)$ and postfeeding (ם) plasma NEFA concentrations from Holstein (A) or Jersey (B) calves. Interaction $(P<0.05)$ of sampling time and week for Holsteins and $(P=0.06)$ for Jerseys.

(Webb et al., 1969). At the beginning of life, calves were more dependent on MR as their main dietary energy source and therefore mobilized NEFA before the morning MR feeding. As calves began relying on calf starter as their primary nutrient source and were free to eat throughout the day, NEFA concentrations became similar for the two sampling times.

Least squares means for pre- and postfeeding plasma glucose concentrations are shown in Figure 6. There was an interaction of week and sampling time $(P<$ $0.05)$ for plasma glucose concentrations in Holstein and Jersey calves. From wk 1 to 5 , in response to feeding, plasma glucose concentrations rose at $30 \mathrm{~min}$ postfeeding in the Holstein calves and at 60 min postfeeding in the Jersey calves. At wk 6, when calves were weaned, plasma glucose concentrations were similar for all six sampling times. Pre- and postfeeding concentrations of 

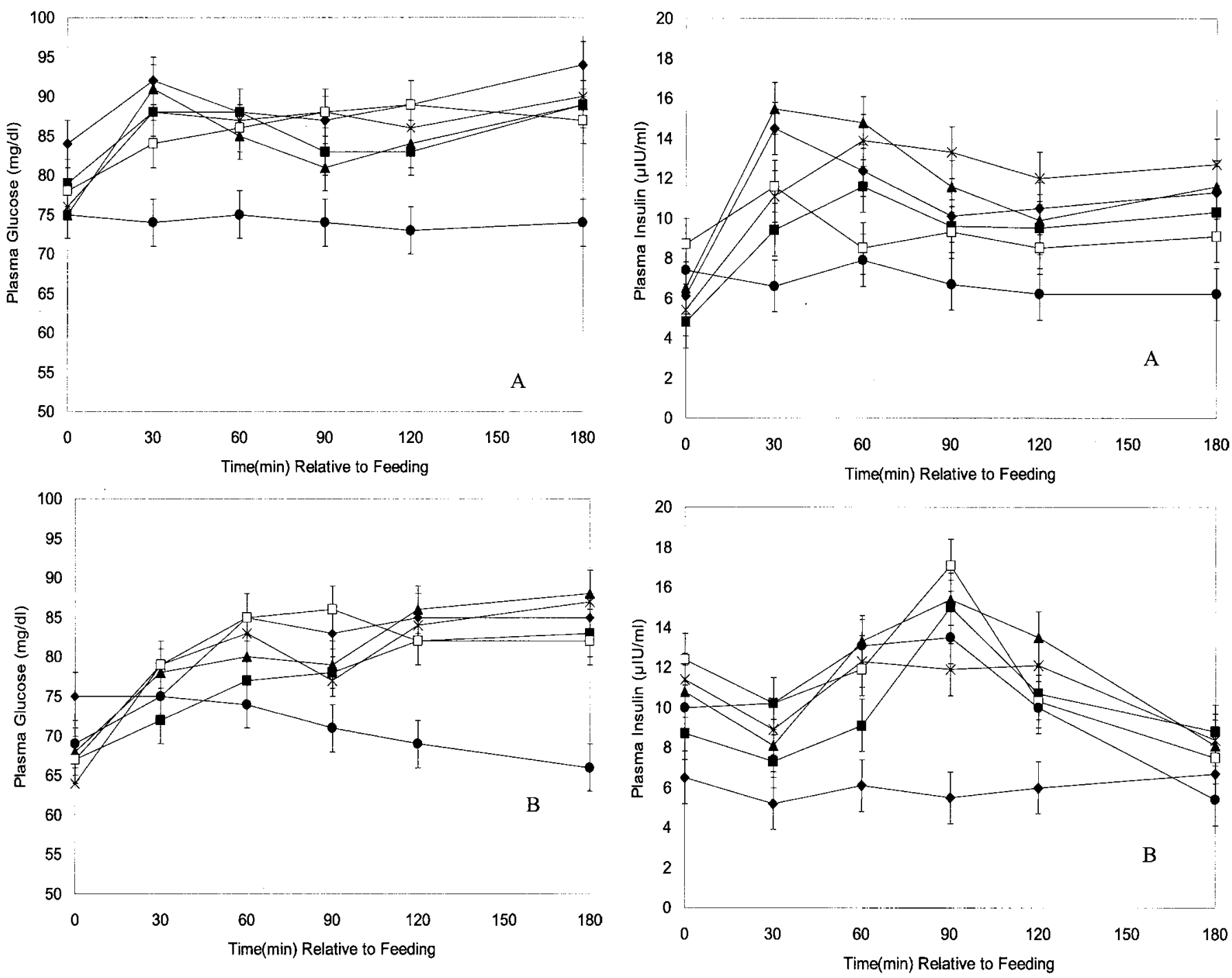

Figure 6. Least squares means for pre- and postfeeding plasma glucose concentrations from Holstein (A) or Jersey (B) calves for wk $1(\diamond), 2(\square), 3(\boldsymbol{\Delta}), 4(\mathrm{x}), 5(\square)$, and $6(\bullet)$. Interactions $(P<0.05)$ of sampling time and week for Holsteins and Jerseys.

plasma glucose declined with age in all calves regardless of MR feeding frequency. DePew et al. (1998) and Bunting et al. (2000) reported decreasing glucose concentrations relative to MR feeding in calves during the preweaning phase as calves aged. Quigley et al. (1991) reported that postfeeding plasma glucose concentrations declined with age.

Least squares means for pre- and postfeeding plasma insulin concentrations for calves are shown in Figure 7. There was an interaction of week and sampling time $(P<0.05)$ for plasma insulin concentrations in Holstein and Jersey calves. Insulin peaked at $60 \mathrm{~min}$ for Holsteins and at 120 min for Jersey calves. Pre- and postfeeding insulin concentrations increased in all calves

Figure 7. Least squares means for pre- and postfeeding plasma insulin concentrations from Holstein (A) and Jersey (B) calves for wk $1(\bullet), 2(\square), 3(\mathbf{\Delta}), 4(\mathrm{x}), 5(\square)$, and $6(\bullet)$. Interactions $(P<0.05)$ of sampling time and week for Holsteins and Jersey.

during the weeks before weaning. However, after weaning, insulin concentrations decreased for all times relative to feeding. DePew et al. (1998) and Bunting et al. (2000) reported that insulin concentrations increased with age in calves fed MR prior to weaning. Donkin and Armentano (1995) reported that insulin concentrations declined as calves developed from the preruminating state to the ruminating state.

Least squares means for plasma glucagon concentrations for wk 1 through 6 and wk 8 are presented in Table 4. In both experiments, plasma glucagon concentrations changed as calves aged $(P<0.05)$. During the first $2 \mathrm{wk}$, calves consumed MR as their primary nutrient source without eating starter steadily throughout the day. 
Table 4. Least squares means for plasma glucagon concentrations.

\begin{tabular}{lllllr}
\hline & \multicolumn{2}{c}{ Holstein calves } & & \multicolumn{2}{c}{ Jersey calves } \\
\cline { 2 - 3 } Week & $\begin{array}{l}\text { Plasma glucagon } \\
(\mathrm{pg} / \mathrm{ml})^{\mathrm{a}}\end{array}$ & SEM & & $\begin{array}{l}\text { Plasma glucagon } \\
(\mathrm{pg} / \mathrm{ml})^{\mathrm{a}}\end{array}$ & SEM \\
\hline 1 & 111.9 & 7.6 & & 104.4 & 10.0 \\
2 & 94.0 & 7.6 & & 84.2 & 8.1 \\
3 & 74.1 & 7.6 & & 68.0 & 6.5 \\
4 & 71.5 & 7.6 & & 68.4 & 6.6 \\
5 & 72.0 & 7.8 & & 85.6 & 8.2 \\
6 & 80.9 & 7.6 & & 86.1 & 8.3 \\
8 & 94.0 & 7.6 & 86.9 & 8.3 \\
\hline
\end{tabular}

${ }^{\mathrm{a}}$ Main effect of week $(P<0.05)$.

Higher plasma glucagon concentrations during this period may be attributed to calves being in a fasted state before the MR feeding. During wk 3 and 4, calves began consuming starter throughout the day and relied less upon the MR as a primary source of nutrients. Glucagon concentrations during this period decreased compared to the first 2 wk of life. During wk 5 to 8 , MR intake was reduced, calves were weaned, starter intake increased, and glucagon concentrations increased. During this time hepatic gluconeogenesis probably increased as the result of an increase in VFA production and absorption as a result of increased starter intake and rumen development (Owens et al., 1986). Since glucagon is the hormone responsible for controlling gluconeogenesis, it was expected that its concentration would increase with age (Owens et al., 1986).

\section{Frequently Sampled Intravenous Glucose Tolerance Tests}

Least squares means for $\mathrm{S}_{\mathrm{G}}, \mathrm{S}_{\mathrm{I}}$, and $\mathrm{AIR}_{\text {glucose }}$ for calves fed MR once daily versus twice daily are reported in Table 5. The $S_{G}$ and $S_{I}$ were similar $(P>0.10)$ for calves fed MR once or twice daily in both experiments. The AIR glucose was higher in Holstein $(P<0.05)$ and Jersey calves $(P=0.06)$ fed MR twice daily, indicating that the insulin response to glucose administration was greater with more frequent feeding. Calves that were fed MR once daily may have been metabolically condi- tioned to ingesting a large amount of glucose at once, which could explain the lower AIR $_{\text {glucose }}$ in these animals. It is also possible that although there were no differences in $\mathrm{S}_{\mathrm{I}}$ or $\mathrm{S}_{\mathrm{G}}$, the $\mathrm{AIR}_{\text {glucose }}$ may be an indication of subtle metabolic differences caused by alterations in feeding frequency.

Least squares means for $\mathrm{S}_{\mathrm{I}}, \mathrm{S}_{\mathrm{G}}$, and $\mathrm{AIR}_{\text {glucose }}$ for calves at wk 3 and 6 are presented in Table 6 . It appears that Jersey calves may be more insulin sensitive than Holsteins, as evidenced by the large numerical difference in the $\mathrm{S}_{\mathrm{I}}$ between the two experiments. The $\mathrm{S}_{\mathrm{I}}$ decreased with age for all calves $(P<0.05)$, while AIR $_{\text {glu- }}$ cose increased with age $(P<0.05)$ for all calves. Bunting et al. (2000) reported that as calves aged, $\mathrm{S}_{\mathrm{I}}$ decreased. It has been suggested that calves become insulin resistant as they progress from a nonruminant to a ruminant state (Hugi et al., 1997). Therefore it seems reasonable that as calves age and become insulin resistant, more insulin is required to accomplish homeostasis when challenged with a glucose load.

\section{CONCLUSIONS}

Feeding calves MR once daily or twice daily did not affect starter consumption or weight gain or adversely effect glucose metabolism. Overall, MR feeding frequency did not affect plasma NEFA, glucose, insulin, glucagon concentrations or urinary glucose concentrations. FSIGT data confirm that feeding calves MR once daily does not increase insulin resistance or negatively effect glucose metabolism. These data indicate that there may be evidence of metabolic differences between Holstein and Jersey calves.

\section{ACKNOWLEDGMENTS}

The authors appreciate the assistance of the faculty, staff, and student workers at the Dairy Science Research and Teaching Farm in Baton Rouge, LA and at Hill Farm Research Station in Homer, LA. The authors wish to thank Laura Gentry, Andra Ponson, Jessica Lannes, and Mike Stanley for their technical assis-

Table 5. Least squares means for insulin sensitivity $\left(\mathrm{S}_{\mathrm{I}}\right)$, glucose effectiveness $\left(\mathrm{S}_{\mathrm{G}}\right)$, and acute insulin response $\left(\mathrm{AIR}_{\text {glucose }}\right)$ for calves fed milk replacer $(\mathrm{MR})$ once $(1 \times)$ versus twice $(2 \times)$ daily.

\begin{tabular}{lccccccc}
\hline & \multicolumn{3}{c}{ Holstein calves } & & \multicolumn{3}{c}{ Jersey calves } \\
\cline { 2 - 3 } & MR $2 \times$ & MR $1 \times$ & SEM & & MR $2 \times$ & MR $1 \times$ & SEM \\
\hline $\mathrm{S}_{\mathrm{I}}, 10^{-4} \mathrm{~min}^{-1} / \mu \mathrm{Uml}$ & 13.6 & 15.3 & 1.6 & & 24.7 & 23.1 & 4.0 \\
$\mathrm{~S}_{\mathrm{G}}, \times 100 \mathrm{~min}^{-1}$ & 0.024 & 0.023 & 0.002 & & 0.024 & 0.024 & 0.003 \\
$\mathrm{AIR}_{\text {glucose }}, \mu \mathrm{IU} / \mathrm{ml}^{\mathrm{a}, \mathrm{b}}$ & 157.5 & 109.0 & 12.3 & & 139.4 & 92.1 & 16.8 \\
\hline
\end{tabular}

${ }^{\mathrm{a}}$ Main effect of MR feeding frequency (Holstein calves; $P<0.05$ ).

${ }^{\mathrm{b}}$ Main effect of MR feeding frequency (Jersey calves; $P=0.06$ ). 
Table 6. Least squares means for insulin sensitivity $\left(S_{I}\right)$, glucose effectiveness $\left(S_{G}\right)$, and acute insulin response $\left(\mathrm{AIR}_{\text {glucose }}\right)$ for calves at weeks 3 and 6 .

\begin{tabular}{lccccccc}
\hline & \multicolumn{3}{c}{ Holstein Calves } & & \multicolumn{3}{c}{ Jersey Calves } \\
\cline { 2 - 3 } & wk 3 & wk 6 & SEM & & wk 3 & wk 6 & SEM \\
\hline $\mathrm{S}_{\mathrm{I}}, 10^{-4} \mathrm{~min}^{-1} / \mu \mathrm{Uml}^{\mathrm{a}}$ & 18.1 & 10.5 & 1.5 & & 29.7 & 18.1 & 3.7 \\
$\mathrm{~S}_{\mathrm{G}}, \times 100 \mathrm{~min}^{-1}$ & 0.023 & 0.024 & 0.003 & & 0.025 & 0.023 & 0.003 \\
$\mathrm{AIR}_{\text {glucose }}, \mu \mathrm{IU} / \mathrm{ml}^{\mathrm{a}}$ & 92.4 & 139.1 & 15.3 & & 117.3 & 149.3 & 10.8 \\
\hline
\end{tabular}

${ }^{a}$ Main effect of age (Holstein calves, $P<0.05$; Jersey calves, $P<0.05$ ).

tance. The support of Moorman's, Inc., Quincy, IL, is greatly appreciated.

\section{REFERENCES}

Anderson, K. L., T. G. Nagaraja, J. L. Morrill, T. B. Avery, S. J. Galitzer, and J. E. Boyer. 1987. Ruminal microbial development in conventionally or early weaned calves. J. Anim. Sci. 64:1215-1226.

Bergman, R. N. 1997. The minimal model: Yesterday, today, and tomorrow. Pages 51-123 in The Minimal Model Approach and Determinants of Glucose Tolerance. R. N. Bergman and J. C. Lovejoy, eds. Louisiana State Press, Baton Rouge.

Bunting, L. D., T. A. Tarifa, B. T. Crochet, J. M. Fernandez, C. L. DePew, and J. C. Lovejoy. 2000. Effects of dietary inclusion of chromium propionate and calcium propionate on glucose disposal and gastrointestinal development in dairy calves. J. Dairy Sci. 83:2491-2498.

DePew, C. L., L. D. Bunting, J. M. Fernandez, D. L. Thompson, Jr., and R. W. Adkinson. 1998. Performance and metabolic responses of young dairy calves fed diets supplemented with chromium tripicolinate. J. Dairy Sci. 81:2916-2923.

Donkin, S. S., and L. E. Armentano. 1995. Insulin and glucagon regulation of gluconeogenesis in preruminating and ruminating bovine. J. Anim. Sci. 73:546-551.

Drackley, J. K., J. J. Veenhuizen, M. J. Richard, and J. W. Young. 1991. Metabolic changes in blood and liver of dairy cows during either feed restriction or administration of 1,3-butanediol. J. Dairy Sci. 74:4254-4264.

Galton, D. M., and W. J. Brakel. 1976. Influence of feeding milk replacer once versus twice daily on growth, organ measurements, and mineral content of tissues. J. Dairy Sci. 59:944-948.

Guyton, A. C., and J. E. Hall. 1996. Pages 971-983 in Textbook of Medical Physiology. 9th ed. W. B. Sanders Company, Philadelphia, PA.
Hammon, H., and J. W. Blum. 1998. Endocrine and metabolic changes in neonatal calves in response to growth hormone and long- $\mathrm{R}^{3}$ insulin-like growth factor-I administration. Biol. Neonate 73:121-128.

Hostettler-Allen, R. L., L. Tappy, and J. W. Blum. 1994. Insulin resistance, hyperglycemia, and glucosuria in intensively milk-fed calves. J. Anim. Sci. 72:160-173.

Hugi, D., R. M. Bruckmaier, and J. W. Blum. 1997. Insulin resistance, hyperglycemia glucosuria, and galactosuria in intensively fed veal calves: Dependency on age and effects of high lactose intake. J. Anim. Sci. 75:469-482.

Littell, R. C., P. R. Henry, and C. B. Ammeran. 1998. Statistical analysis of repeated measures data using SAS procedures. J. Anim. Sci. 76:1216-1231.

Owens, S. W., J. L.Sartin, R. J. Kemppainen, K. A. Cummins, F. F. Bartol, and A. Bowman. 1986. Developmental alterations in the regulation of glucagon and insulin secretion in Holstein calves. Am. J. Vet. Res. 47:263-269.

Quigley, J.D., III, L. A. Caldwell, G. D. Sinks, and R. N. Heitmann. 1991. Changes in blood glucose, nonesterified fatty acids, and ketones in response to weaning and feed intake in young calves. J. Dairy Sci. 74:250-257.

Quigley, J. D. 1996. Influence of weaning method on growth, intake, and selected blood metabolites in Jersey calves. J. Dairy Sci. 79:2255-2260.

SAS/STAT User's Guide: Statistics, Version 6, 4th Edition. 1989. SAS Inst., Inc., Cary, NC.

Vicini, J. L., F. C. Buonomo, J. J. Veenhuizen, M. A. Miller, D. R. Clemmons, and R. J. Collier. 1991. Nutrients balance and stage of lactation affect responses of insulin, insulin-like growth factors I and II, and insulin-like growth factor-binding protein 2 to somatotropin administration in dairy cows. J. Nutr. 121:1656-1664.

Webb, D. W., H. H. Head, and C. J. Wilcox. 1969. Effect of age and diet on plasma glucose levels, plasma nonesterified fatty acid levels, and glucose tolerance in dairy calves. J. Dairy Sci. 52:2007-2013.

Wijayasinghe, M. S., N. E. Smith, and R. L. Baldwin. 1984. Growth, health, and blood glucose concentrations of calves fed high-glucose or high-fat milk replacers. J. Dairy Sci. 67:2949-2956. 